\title{
Effects of the phase interface on initial spallation damage nucleation and evolution in dual phase titanium alloy
}

\author{
Y. Yang ${ }^{\mathrm{a}, \mathrm{b}, \mathrm{c}, \mathrm{d}, *}$, Z. Jiang ${ }^{\mathrm{a}}$, C. Wang ${ }^{\mathrm{a}}$, H.B. Hu ${ }^{\mathrm{b}}$, T.G. Tang ${ }^{\mathrm{b}}$, H.S. Zhang ${ }^{\mathrm{c}}$, Y.N. Fu ${ }^{\mathrm{e}}$ \\ a School of Material Science and Engineering, Central South University, Changsha 410083, China \\ ${ }^{\mathrm{b}}$ Institute of Fluid Physics, China Academy of Engineering Physics, Mianyang 621900, China \\ ${ }^{c}$ Institute of mechanics, Chinese Academy of Sciences, Beijing 100190, China \\ ${ }^{\mathrm{d}}$ Key Laboratory of Nonferrous Metals Material Science and Engineering of Ministry of Education, Central South University, Changsha 410083, China \\ e Shanghai Institute of Applied Physics, Chinese Academy of Sciences, Shanghai 201800, China
}

\section{A R T I C L E I N F O}

\section{Keywords:}

Spallation

Phase interface

Voids nucleation

XRCT

EBSD

Ti-6Al-4V

\begin{abstract}
A B S T R A C T
The Ti-6Al-4V dual phase alloy samples were dynamic loaded by one-stage light gas gun experiment and samples with initial spallation were softly recovered. During the loading experiment, the velocity of free surface particles was measured by photonic doppler velocimetry (PDV). The effect of $\alpha / \beta$ phase interface on nucleation, growth, and coalescence of dynamic damage in Ti-6Al-4V were investigated by 2-D or 3-D testing techniques, such as optical microscopy(OM), x-ray computer tomography(XRCT), and electron backscattered diffraction(EBSD). The results showed that the majority of voids were nucleated within $\alpha$ phases, rather than on the $\alpha / \beta$ phase interface as predicted by quasi-static damage theory. Due to the effects of reflection and transmission of shock wave at the phase interface, a tensile pulse would be formed within $\alpha$ phase when the shock wave transmit from $\alpha$ phase with high impedance to $\beta$ phase with low impedance. When this tensile pulse was large enough, voids would be formed within $\alpha$ phase. The analyses of OM and XRCT indicated that the voids at the beginning of nucleation were nearly spherical, then grew up along the direction of $45^{\circ}$ with the shock loading direction, and finally the rod-shaped voids were formed. Besides, the voids were not randomly nucleated within $\alpha$ phase, and the EBSD analysis showed that the voids were mainly nucleated at grain boundary triple points which composed of grains with large difference of Taylor Factor(TF) value within $\alpha$ phase. This is because the difference of plastic deformation capacity of this grains is larger, and it is easier to produce stress concentration. Thus these sites became the prior nucleation position of voids.
\end{abstract}

\section{Introduction}

Spallation is a typical material dynamic failure mode, which is closely related to the dynamic unloading behavior of materials; the tensile stress was produced by the collision of two rarefaction waves under shock loading, which caused micro-damage nucleation, growth, coalescence and ultimate fracture within the materials [1,2]. Due to the research on the phenomenon of spallation is not only closely related to military engineering, aviation and space engineering, but also involves various disciplines, therefore the spallation research has important practical and theory significance, and has been widely investigated. However, because of the need of weapon physics research, the spallation behavior is mainly concerned by engineering physics and mechanics workers, and the related researches of material science were seriously lacking.

The discovery of spallation began in 1914, Hopkinson [3] put a piece of dynamite on the steel plate, and found that there was scab flying out of the back surface. He analyzed the experimental phenomena and believed that the spallation was caused by the interaction of shock wave generated by the explosion in the material, which caused the material to be subjected to tensile stress to produce the scab flying out. In the early 1950s, Rinehart [4] used the method of Hopkinson to obtain the spallation state of some materials such as aluminum alloy, brass, copper and steel, and they thought the spall strength is one of the material characteristic parameters. Meyers and Aimone [5] had made a systematic summary and review of the main research conclusions about the damage of spallation before 1983. Davison and Grady [6], as well as Curran and seaman [7], had comprehensively reported on various loading techniques, diagnostic methods and experimental results in the field of spallation research. Antoun et al. [1] made authoritative comments on the study history and current situation of spalltion. Williams et al. [8] introduced the latest research findings and advances.

\footnotetext{
* Corresponding author at: School of Materials Science and Engineering, Central South University, Changsha 410083, China.

E-mail address: yangyanggroup@163.com (Y. Yang).
} 
With the further study on the damage of spallation, the influences of material's shape, microstructure and methods of dynamic loading on the fracture resistance of materials had been the hot spots of research in the field of dynamic tensile fracture. Koskelo [9] discovered that the damage of plate impact appeared in the regions where prone to generate a large number of dislocation during the shock-loading, and the damage continued to grow with the cyclic effect of the subsequent shock wave. According to Furnish et al. [10], the nucleation position of tantalum metal spalled samples in the plate impact test was related to the original grain size of the sample, and compared with the high stress state, the effect of microstructure on the spallation behavior under the low stress state is more obvious. In poly-crystalline copper, the study confirmed that grain boundary is the main nucleation point of voids in the primary spallation samples [11,12]. The author [13-16] also used the high purity copper as the research object, and studied the influence law and mechanism of different loading methods, shape of sample and the "grain boundary effect"(grain boundary type, grain orientation and grain size) on the spallation behavior of high purity metals. A great deal of previous work had focused on the study of spallation of single-phase pure metal, however, multiphase alloys were widely used in modern engineering. There were few researches on the influence of the phase interface, and the influences law and mechanism of the phase interface on the nucleation and evolution of dynamic damage were not fully understood at present.

Both phase interface and grain boundary were present in multiphase alloy. Phase interface refers to the interface consists of two pieces of crystal with different structure or the same structure but different lattice parameters, and grain boundary refers to the interface between the two grains with same structure but different orientation. It is well known that due to the differences of physical and mechanical properties between two phases, the stress/strain mismatch is easily generated in the phase interface. So the phase interface seems to be a "weak link", and it is the preferred position of voids nucleation and growth, which is the general rule based on the theory of damage fracture under quasistatic loading [17]. Under the impact theory [1,2], dynamic loading process is the propagation of shock wave within material, and phase interface will generate the effect of interaction and reflection on shock wave. Simultaneously, the different properties and performance of different phase may also affect the spread of shock waves. So the research on the influence law and mechanism of the phase interface on the spallation behavior was of great significance for us to further study the spallation.

At present, there are few researches on the effect of phase interface on the behavior of spallation. Work by Minich et al. [18] on two phase materials like single crystal copper with $\mathrm{SiO}_{2}$ inclusions showed that the presence of small, hard $\mathrm{SiO}_{2}$ precipitates reduced the stress required for voids to nucleate in this material as compared to that for pure $\mathrm{Cu}$. Similarly, Christy et al. [19] examined inclusions present at a grain boundary in $\mathrm{Cu}$ revealed that voids preferred to nucleate at these inclusions along the grain boundaries. Fensin et al. [20-22] used the single phase pure copper, $\mathrm{Cu}-\mathrm{Pb}$, and $\mathrm{Cu}-\mathrm{Ag}$ alloy as the objects and found that in the alloy containing the second phase, different content of the second phase will affect and the spall strength and damage degree, and the phase interface will affect the position of the voids. Cerreta et al. [23] studied the spallation behavior of pure copper and Cu- $1 \mathrm{wt} \%$ $\mathrm{Pb}$ alloy under impact loading. The results showed that there was a significant reduction in the damage nucleation of the pure copper without adding lead, but the corresponding velocity of damage evolution was faster. Han et al. [24] studied the dynamic deformation and failure of $\mathrm{Cu}-\mathrm{Nb}$ layered nanocomposites (with a nominal layer thickness of $135 \mathrm{~nm}$ ) under plate impact and found that the incipient voids tend to nucleate within the $\mathrm{Cu}$ phase rather than nucleate along the $\mathrm{Cu}-\mathrm{Nb}$ interfaces. This finding contradicted the general thinking of failure started from interfaces. Yang et al. $[25,26]$ studied the nucleation and growth characteristics of the initial spallation of lead brass, and found that the distribution position of the microvoids was close to the spalled layer and most of the voids were nucleated in the lead phase. Although the above researches and experiment phenomenons showed that the phase interface will affect the spallation strength, but its influences law and mechanism for the nucleation position and evolution of voids in the initial stage of spall were still not clear. At present, there is a lack of systematic and in-depth study on the influence of the phase interface on the behavior of spallation.

Al-6Ti-4V has good plasticity, super-plasticity, weld-ability and corrosion resistance, etc. And because of its excellent mechanical properties as well as the characteristics of easy processing, it has long been used as the candidate materials of military industry manufacture.

\section{Experimental design and procedures}

\subsection{Materials}

In order to investigate the influence of phase interface on the void nucleation of spallation, Ti-6Al-4V dual phase alloy was used as the experimental material. In order to study the effect of phase composition on the spallation behavior simultaneously, different heat treatment regimes were used to obtain two samples with different phase content and grain size. The phase transformation temperature of Ti- $6 \mathrm{Al}-4 \mathrm{~V}$ is $975 \pm 10^{\circ} \mathrm{C}$, which means that when temperature close to $975^{\circ} \mathrm{C}$, the a phase would gradually converted into $\beta$ phase, so the different solid solution temperature can get different phase composition. The two kinds of heat treatment regimes: (1) solution under $937^{\circ} \mathrm{C}$ for $2 \mathrm{~h}$, $700{ }^{\circ} \mathrm{C}$ water quenching for $2 \mathrm{~h}$, air cooling; (2)solution under $947^{\circ} \mathrm{C}$ for $2 \mathrm{~h}, 700^{\circ} \mathrm{C}$ water quenching for $2 \mathrm{~h}$, air cooling. Fig. 1 shows the metallographic diagram.

As can be seen from Fig. 1, both samples were composed of a phase (white) and $\beta$ phase(gray). The composition of a phase and the grain size of two samples were calculated by IPP (image pro plus) software as shown in the Table 1:
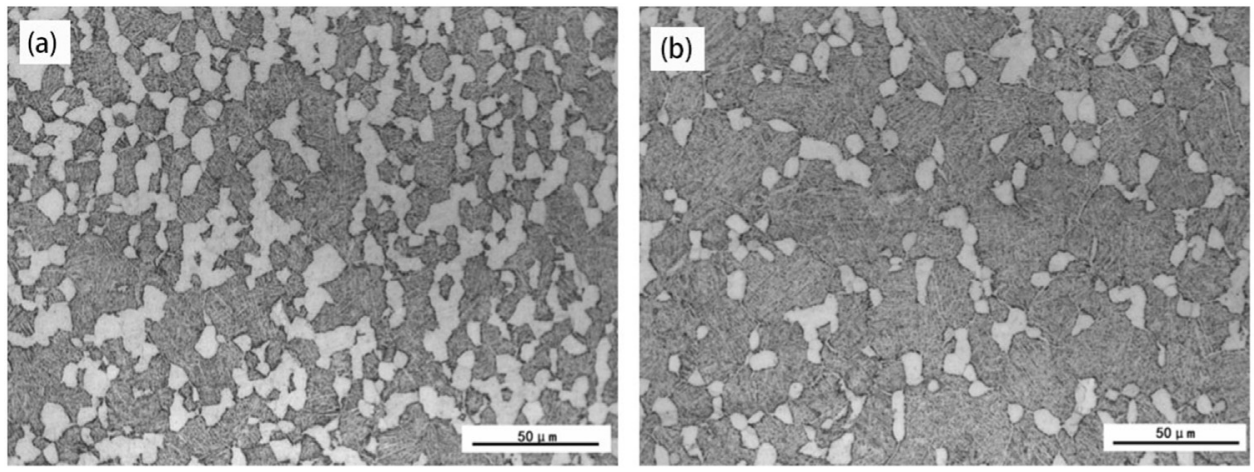

Fig. 1. Metallographic diagrams of two samples after different heat treatment: (a)Sample one (b)Sample two. 
Table 1

Sample heat treatment system and phase composition.

\begin{tabular}{llll}
\hline $\begin{array}{l}\text { Sample } \\
\text { number }\end{array}$ & Heat treatment & $\begin{array}{l}\text { a phase } \\
\text { composition }(\%)\end{array}$ & $\begin{array}{l}\text { Average grain } \\
\text { size }(\mu \mathrm{m})\end{array}$ \\
\hline Sample one & $\begin{array}{l}\text { solution under } 937^{\circ} \mathrm{C} \text { for } \\
2 \mathrm{~h}, 700^{\circ} \mathrm{C} \text { water quenching } \\
\text { for } 2 \mathrm{~h} \text {, air cooling } \\
\text { solution under } 947^{\circ} \mathrm{C} \text { for } \\
2 \mathrm{~h}, 700^{\circ} \mathrm{C} \text { water quenching } \\
\text { for } 2 \mathrm{~h} \text {, air cooling }\end{array}$ & 43.3 & 8.8 \\
Sample two & 31.6 & 7.6 \\
\hline
\end{tabular}

\subsection{Experimental methods}

\subsubsection{Single-stage light gas gun experiment}

In order to obtain the samples with initial spalled state, the singlestage light gas gun experiment was adopted. The experiment was completed at the institute of mechanics of Chinese academy of sciences in Beijing, and the experiment set-up was self-designed. The samples with the size of $\Phi 24 \mathrm{~mm} \times 4 \mathrm{~mm}$ and the flyer with the size of $\Phi 55 \mathrm{~mm} \times 2 \mathrm{~mm}$ were acquired by wire cutting, machining and other materials processing methods. In order to realize the symmetrical impact of the stress wave, the thickness of flyer was designed to be half of the thickness of samples, and the flyer material was the original Ti-6Al$4 \mathrm{~V}$ samples. In order for the two samples subjected to the same impact stress at the same time, this test adopted the loading method of one flyer impacted two samples simultaneously. The target plate was shown in Fig. 2:

The two samples with different heat treatment were separately fixed in the two $\Phi 25 \mathrm{~mm}$ round holes in Fig. 2 by AB glue. In order to get the samples of the initial spalled state, the loading velocity was designed as $440 \mathrm{~m} / \mathrm{s}$. To avoid the second injury, the samples were obtained by soft recovery. The free surface velocity curve of the sample was measured by photonic doppler velocimetry (PDV) system, and the laser probe placed on the free surface of the sample to measure the particle velocity in real time [27].

\subsection{Metallography, XRCT, nanoindentation and EBSD analyses}

In order to study the macroscopic distribution and location of the

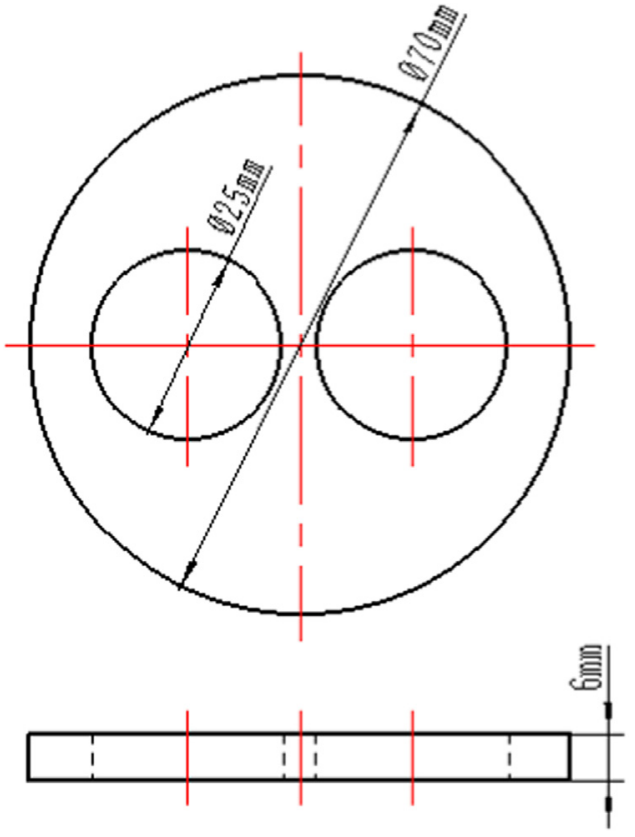

Fig. 2. The target plate of light gas gun experiments. damage in the samples after the impact, the soft recovered samples were analyzed by metallographic analysis. Because of the symmetrical collision of the shock wave, the samples were cut along the radial direction. Firstly, the samples were metallographical analyzed without corrosion. In this paper, EBSD electrochemical polishing was adopted to obtain the uncorroded metallographic samples. And then the metallographical analyzed after corrosion. The metallographic corrosion solution used in this experiment is: $\mathrm{HF}: \mathrm{HNO}_{3}: \mathrm{H}_{2} \mathrm{O}=2 \mathrm{ml}: 5 \mathrm{ml}: 10 \mathrm{ml}$. The erosion time is about $10 \mathrm{~s}$, and cleaned with water immediately after erosion, then rinsed with alcohol. According to the basic principle of spallation formation, different shock impedance of materials would affect the spread of the shock wave, which would finally affects the nucleation and growth of spallation damage [1]. Shock impedance can be approximated as the product of the initial density $\rho_{0}$ and the sonic wave velocity $\mathrm{C}_{0}\left(C_{0} \approx \sqrt{E / \rho_{0}}, \mathrm{E}\right.$ is the Young's modulus, and we use the elastic modulus as an alternative). There was a significant difference between the mechanical properties of $a$ and $\beta$ phase, that is, their impedance is different, which affect the nucleation of the spallation. The elastic modulus and hardness of the two phases can be measured by the nano indentation of CSM company, and the impedance can be estimated according to the density of the two phases. The elastic modulus data obtained by nanoindentation experiment is based on the theory of Oliver \& Pharr [28]. In this experiment, three points were tested in each phase, and the average values of hardness and elastic modulus were obtained.

The soft recovered samples were characterized by XRCT to study the 3-D distribution of damage. The experiments were carried out at the Xray imaging beamline BL13W1 at Shanghai Synchrotron Radiation Facility (SSRF) by using X-ray phase-contrast imaging (PCI) techniques. In order to ensure the sample was fully penetrate, the sample size was designed as $0.5 \times 0.5 \times 4 \mathrm{~mm}$, and the photon energy was $27 \mathrm{keV}$. The exposure time for a single shot was kept at $2 \mathrm{~s}$ and the sample-to-detector distance (SDD) was $8 \mathrm{~cm}$, and the magnification was 20 times. Then the CT images were reconstructed using PITRE software. The analysis of the reconstructed areas with various damage characteristics were executed with Amira 5.4 software.

The dotted line area in Fig. 3 was the sampling location:

The influence of grain orientation and grain boundary type on the nucleation position was analyzed by EBSD test. In the preparation process of EBSD samples, the surface strain layer was removed by electrolytic polishing. The electrolytic polishing fluid was: perchloric acid: methanol: butyl alcohol $=20 \mathrm{ml}: 120 \mathrm{ml}: 60 \mathrm{ml}$, and the voltage was $30 \mathrm{v}$. The temperature is about $30^{\circ} \mathrm{C}$, using liquid nitrogen cooling and polishing about $30 \mathrm{~s}$. In this paper, the experiment was carried out in the electronic double-beam microscopy with EBSD accessory, and the model was HELIOS NanoLab $600 \mathrm{i}$. The voltage used is $20 \mathrm{kV}$, and the step length is $0.5 \mathrm{~mm}$. Using the software of $H K L$-channel.5 to collect EBSD data, and the data packets were processed by the OIM analysis software. The orientation diagram, the grain boundary recomposition and $\mathrm{TF}$ diagram were obtained by indexing the a phase.

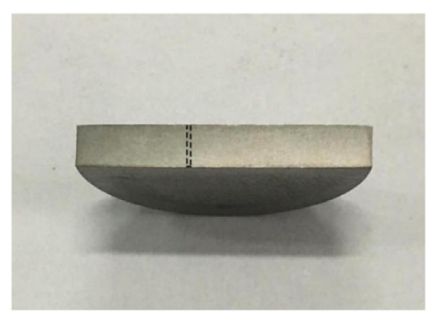

Fig. 3. Sampling method of XRCT sample. 


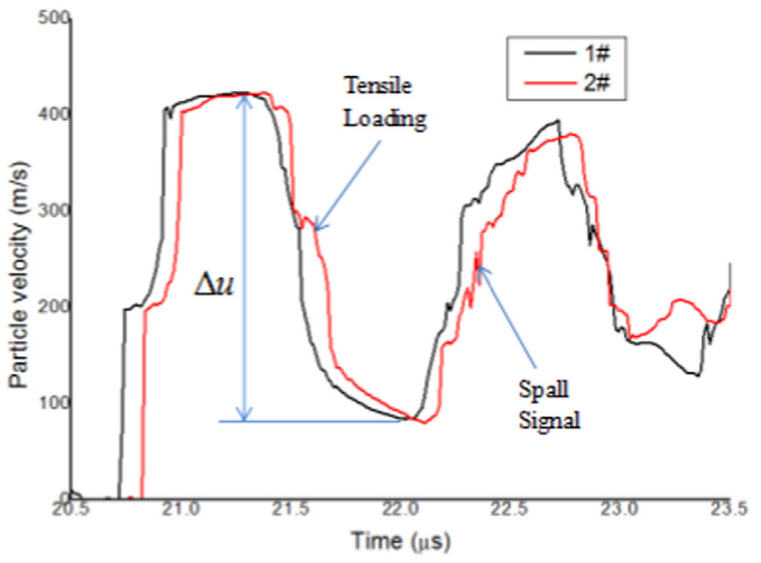

Fig. 4. Free surface velocity curve.

\section{Results and discussion}

\subsection{Free surface velocity curve}

The free surface velocity curve of the loading experiment was acquired by PDV velocity measurement system and show in Fig. 4:

FSV profiles provided in-situ information regarding the motion of shock waves in a sample and can be used to infer the stresses and kinetics associated with voids nucleation and growth [20]. The tensile load was generated when the incoming rarefaction wave from the flyer met the rarefaction waves generated by reflection on the free surface, which refers to the stage of 'Tensile Loading' in Fig. 4. When the tensile load was large enough, there would be the nucleation of spallation damage, and the free surface velocity would rebound, which refers to the stage of 'Spall Signal' in Fig. 4 [29].

The calculation formula of the shock pressure is:

$\sigma_{s}=\rho_{0}\left(c_{b}+s u\right) u$

Where,

$$
U=c_{b}+s u
$$

is often known as the equation of state (EOS) of a material, which describes fairly well the shock response of materials not undergoing phase transitions [2].

Where $\sigma_{s}$ is the shock pressure, $U$ is the shock velocity; $\rho_{0}$ is the density of Ti- $6 \mathrm{Al}-4 \mathrm{~V}\left(4.4 \mathrm{~g} / \mathrm{cm}^{3}\right) ; s$ is the parameter of Gruneisen state equation. And because there was no corresponding data of Ti-6Al-4V, replaced it with the data of pure titanium (1.066) [1]. Bulk sound speed $\left(c_{b}\right)$ is $4.79 \mathrm{~km} / \mathrm{s}$. To simplify the calculation, took half of $\mathrm{W}$ as an approximation of $u$, where $u$ was the velocity of the post-wave particle and $\mathrm{W}$ was the corresponding peak free surface velocities $(0.21 \mathrm{~km} / \mathrm{s})$. The shock pressure of the two samples calculated was about $4.63 \mathrm{GPa}$.

The damage rate discussed usually corresponds (practically without any delay) to the time at which the tensile stress on the spall plane reaches spall strength, and the initial damage rate $\left(\dot{\varepsilon}_{v}\right)$ of the actual tensile stress can be expressed by the following empirical formula:

$\dot{\varepsilon_{v}}=-\frac{1}{2 C_{b}} \frac{d F S V}{d t}$

With regard to the calculation of spall strength, Novikov [30] put forward the formula for estimating the spall strength under acoustic approximation:

$\sigma_{f}=\frac{1}{2} \rho_{0} c_{b} \Delta u$

Where $\Delta u=u_{\max }-u_{\min }$

$\dot{\varepsilon}_{v}$ is the initial damage rate $\left(\mu \mathrm{s}^{-1}\right), \sigma_{f}$ is the spall strength. The $\Delta u$ (pullback velocity) is defined as the difference between the peak value and the valley value of the free surface velocity curve $\left(u_{\max }-u_{\min }\right)$
Table 2

parameters of free surface velocity curve.

\begin{tabular}{llllll}
\hline $\begin{array}{l}\text { Sample } \\
\text { number }\end{array}$ & $\sigma_{s} /(\mathrm{GPa})$ & $\mathrm{EOS}$ & $\Delta \mathrm{U} /(\mathrm{m} / \mathrm{s})$ & $\sigma_{f} /(\mathrm{GPa})$ & $\dot{\varepsilon}_{v} /\left(\mu \mathrm{s}^{-1}\right)$ \\
\hline Sample one & \multirow{2}{*}{4.63} & \multirow{2}{*}{$U=4.79+1.066 \mathrm{u}$} & 338.68 & 3.998 & 0.047 \\
Sample two & & & 342.65 & 4.045 & 0.049 \\
\hline
\end{tabular}

and was often used as the basis for the prediction of the spallation strength.

Considering the influence of elastic-plastic deformation, Stepanov et al. [31] made the following modifications to the equation:

$\sigma_{f}=\rho_{0} c_{l} \Delta u \frac{1}{1+c_{l} / c_{b}}$

Where $c_{l}=6.1 \mathrm{~km} / \mathrm{s}$ is the longitudinal sound speed of Ti-6Al-4V.

The spall strength was calculated by the modified equation, and the results were listed in Table 2 :

Since the loading speed was the same, the shock pressure and the EOS of the two samples were the same. The spall strength of the two samples were $3.998 \mathrm{GPa}$ and $4.045 \mathrm{GPa}$ respectively. The difference was not very large, but the sample two is slightly higher, which indicate that sample two was more difficult to generate spallation under the same loading condition. The initial damage rate $\left(\dot{\varepsilon}_{v}\right)$ was approximately equal to the product of the density of the nucleation position and the growth rate of the void, and the difference between the two samples was very small.

Different organizational structure of materials would affect the nucleation and growth of spall damage. The two samples with different heat treatment technology have different phase composition and the a phase component of sample one was more than that of sample two. Through the multidimensional analyses in the following, most of the voids were nucleated within the a phase. This suggested that sample one (which has more a phase than sample two) had much more nucleation sites, which decreased the spall strength and made the spallation easier to occur.

\subsection{2-dimensional analysis of spallation damage}

The uncorroded metallographical diagram was obtained by electrolytic polishing. The macroscopic distribution of the spallation damage of the sample cross section is shown in Fig. 5:

As can be seen from Fig. 5, the macroscopic crack and obvious damage area were concentrated on both sides of the cross section, while the middle position only had relatively scattered voids and microcracks. The distance between the two samples was relatively close because of the loading method of one flyer hit the two samples at the same time, and the tensile pulse would be released along the radial direction. So the stress wave would be sparse at the boundary of samples and interfere with each other, making the stress field on both sides complicated and lead to the increased void linkage [32]. The intermediate region of the middle layer of the cross section was the pure one-dimensional strain zone. Hence, In order to study the characteristics of incipient spallation more accurately, the damage in the center of the samples as delineated by the black box was investigated, as shown in Fig. 5 [21].

By comparing the damage characteristics of the two samples with different heat treatment, found that damage of sample one was relatively fragmented and mainly composed of scattered voids as well as microcracks. However, sample two had already formed the comparatively obvious cracks, and the voids were fewer than sample one.

After the samples were corroded, the microstructure of the two samples in the above black box area was shown in Fig. 6:

In Fig. 6,the white phase is a phase, the gray phase is $\beta$ phase, the black ball and rod are all voids, and the black arrow indicated the shock 


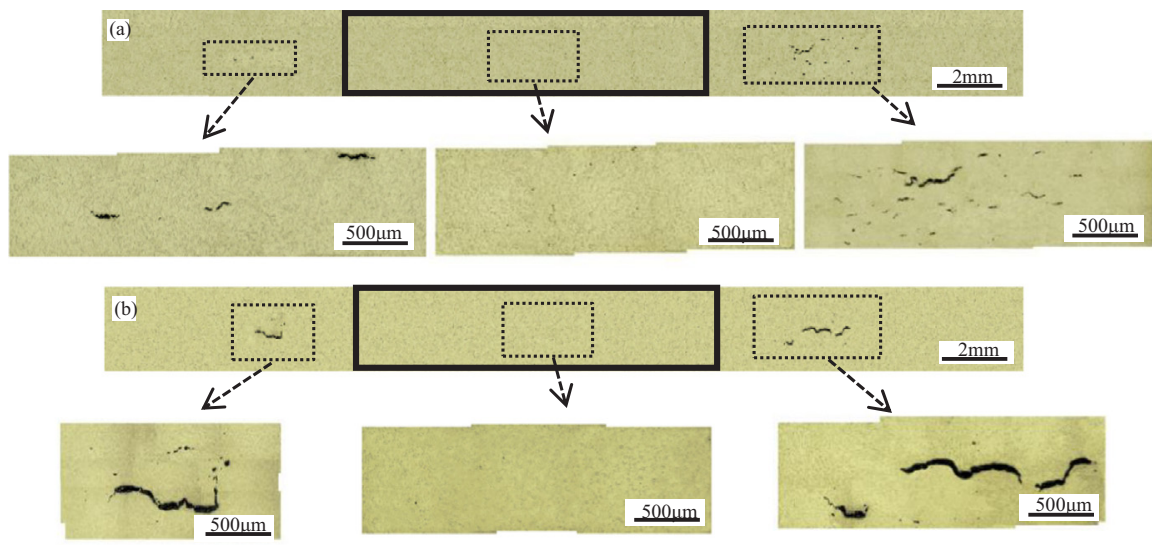

Fig. 5. Macroscopic distribution of spallation damage of the sample cross section after loading(a) sample one (b) sample two.

direction. (1)-(4) are the enlarged view of the corresponding area of (a) and (b). As can be seen from the figure, the voids were nucleated within the a phase, and the voids were nearly spherical in the incipient stage (Fig. 6(1)). And then affected by the shock stress, voids grew up along the direction which was $45^{\circ}$ with the shock loading direction, namely formed rod-shaped voids (Fig. 6(2),(3),(4)). Finally, the voids coalesced with each other and cracks formed(Fig. 6(a)). Because the superficial area and surface energy of sphere are relatively smaller, the voids were mostly spherical at the incipient stage of spallation. For the ductile material, due to the good toughness, the local tensile stress in the deformation stage was relatively uniform. Once the defect was formed, it can be homogenized in a short distance and formed the spherical void. In the process of growing up, the shear tensile stress produced by shock is the largest in the direction of $45^{\circ}$ with the shock loading direction, and the voids and microcrack would be extended along the direction
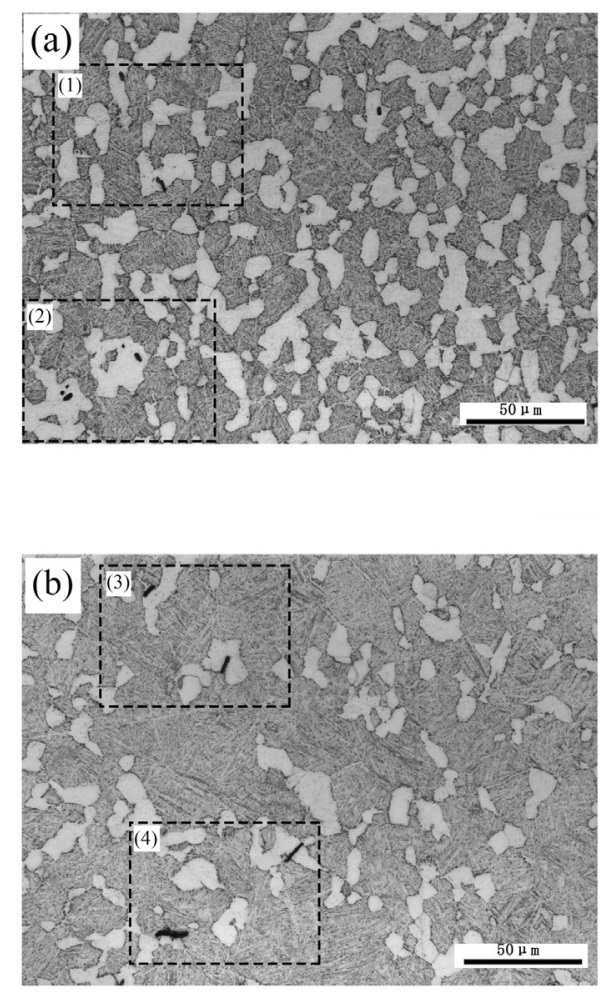

with the maximum shear stress. Through observation, the damage was found to be transgranular fracture, penetrating through the whole a phase and extending to the nearby $\beta$ phase.

Under quasi-static loading, the differences of physical and mechanical properties between two phase were easy to cause the differences of stress/strain on the interface of the two phase, and easily to produce stress concentration at the interface. Thus phase interface is a "weak link", which is often the prior location of the void nucleation and growth under quasi-static loading. However, under dynamic loading, the voids didn't nucleated at the interface as predicted by the theory of quasi-static damage, but nucleated within the a phase.

\subsection{3-dimensional analysis of spallation damage}

The two samples were reconstructed in 3-dimensional, and Fig. 9
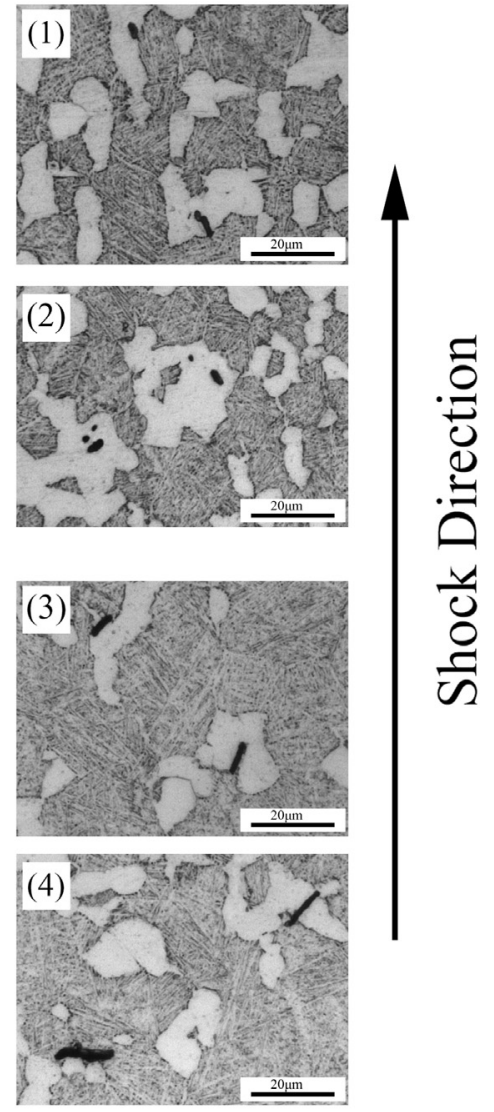

Fig. 6. The microstructure of the samples after the corrosion(a) sample one (b) sample two. 

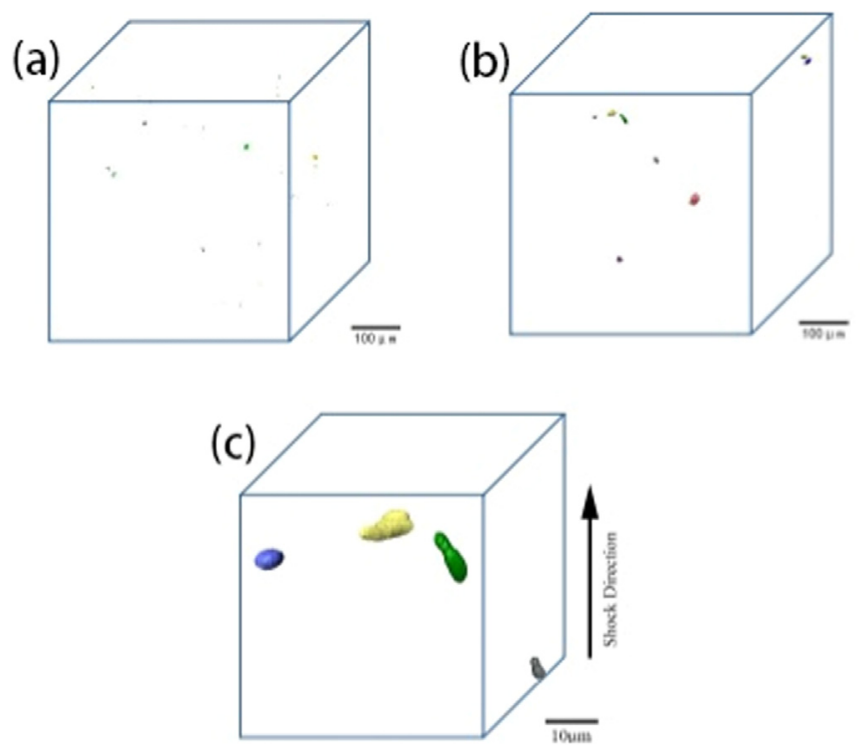

Fig. 7. 3-D reconstruction of the voids distribution in two spalled samples (a) Sample one (b) Sample two (c) enlarged view of the corresponding area.

Table 3

The quantitative statistics of characteristic parameters of voids in two samples.

\begin{tabular}{lllll}
\hline $\begin{array}{l}\text { Sample } \\
\text { number }\end{array}$ & Numbers & $\begin{array}{l}\text { Max volume } \\
\left(\mu \mathrm{m}^{3}\right)\end{array}$ & $\begin{array}{l}\text { Mean volume } \\
\left.\mu \mathrm{m}^{3}\right)\end{array}$ & $\begin{array}{l}\text { Average diameter } \\
(\mu \mathrm{m})\end{array}$ \\
\hline Sample one & 26 & 799.40 & 152.15 & 4.36 \\
Sample two & 8 & 1236.96 & 270.22 & 6.42 \\
\hline
\end{tabular}

was the 3-D spatial distribution of voids. In the experiment of XRCT, because the difference of density between the two phase of Ti-6Al-4V is small, the two phases couldn't be distinguished within the energy range of SSRF, which means only the voids could be identified. In Fig. 7, different colors represent voids in different positions. Table 3 is the correlated data statistics of XRCT.

By analyzing and comparing the data of the two samples in Table 3, the number and density of voids in sample one were more than sample two, while the max and mean volume were smaller than that of sample two. This further verified the results of the free surface velocity curve and the metallography: because the content of a phase in sample one was larger than that of sample two, sample one owns more nucleation sites. This would lead to more voids and the spall strength reduced in sample one. The growth rate of voids in sample two is higher, which lead to the larger size of voids in sample two.

Fig. 7(c) is a partial enlargement of the dashed box in Fig. 7(b). The black arrow is the shock direction. The voids were nearly spherical in the incipient stage, and then affected by the shock stress, voids grew up along the direction which was $45^{\circ}$ with the shock loading direction. The nucleation and the shape changes in the process of growing up showed a certain law, which were consistent with the 2-dimensional analysis.

\subsection{Influence of phase interface on void nucleation}

The nano indentation experiments of the two phases were carried out by taking three test points respectively. Fig. 8 showed the indentation of two test points. Fig. 9 was the displacement-load loading and unloading curves of $\alpha$ phase and $\beta$ phase.

Impedance value calculation formula could be expressed as : $Z=\rho_{0} \times C_{0}[1]$. The sound velocity $C_{0}$ was calculated by the formula mentioned above. The density of the two phases was determined by the energy spectrum analysis measured by scanning electron microscope(SEM) and the composition of different elements in the two phases. The relevant parameters and data were calculated by the software in the lab, and shown in Table 4:

From Table 4, the nano-hardness, elastic modulus, sound velocity, and estimation of the impedance of a phase were all larger than that of $\beta$ phase.

Dynamic loading process is the propagation of shock wave in material, phase interface can produce interaction and reflection of shock wave, and different phase with different shock impedance may also affect the spread of shock waves and the nucleation sites of voids. According to the relevant literature $[1,24]$, when the shock wave propagated between two materials with different impedance, there would be two situations:

(1) Shock wave transmit from material I with high impedance to material II with low impedance. This pressure would produce a release pulse to be sent through material I. Assumed that both I and II were semi-infinite and that the release pulse can travel freely until it encountered the release portion of the primary pulse and a tensile pulse would be formed within material I. If this tensile pulse was large enough, a spallation would be formed.

(2) Shock wave transmit from material II with low impedance to material I with high impedance. When the shock reached the interface, the pressure increased (impedance from low to high). There was a pressure wave spread into material I, and the another pressure wave spread into material II. Hence there were only compression pulses formed in both of phases, and it was not likely that spall would be formed in either the material I or II in this case.

As shown in Fig. 10, when shock wave transmit from material I with high impedance to material II with low impedance, the tensile pulse would be formed at $t_{4}$ in material $I$, thus lead to the formation of spallation damage. In this paper, the experimental material is Ti-6Al-4V (two-phase titanium alloy), and the impedance of the two phases was calculated by the previous experiment. Therefore, under the dynamic loading, when the shock wave was propagated from the a phase with high impedance to $\beta$ phase with low impedance, the voids would be nucleated within the a phase, which is also consistent with the experimental phenomena obtained in the previous multi-dimentional analyses in this paper.

\subsection{Influence of grain boundaries within a phase on the nucleation and growth of voids}

The author [13-16] had discussed in detail the influence law and mechanism of grain boundary on the nucleation and growth of voids, and the grain boundary in the a phase also influenced the nucleation and growth of the voids.

Fig. 11 is the orientation map near the voids in the two samples. Fig. 11 (c) is the quality comparison diagram of EBSD of (b) region. It can be seen that the white a phase in the diagram was composed of many grains, which were not eroded in the metallographic diagram (Fig. 1). Within a phase, the shape of grains is more uniform and the grain size is larger. On the contrary, the shape of grains is irregular and the grain size is smaller in $\beta$ phase. From Fig. 11(a),(b), it can be seen that the voids were nucleated at the grain boundaries with large orientation difference, and mostly nucleated at the grain boundary triple points, such as (1) (2). This is because grain boundary itself has a strong resistance to the slide of the dislocation, so grain boundary triple points were easy to produce the dislocation pile-up. Simultaneously, under the effect of shock wave, grain boundary triple points were the sites which prone to produce stress concentration. In this case, the triple points became the weak position of Ti-6Al-4V, and were easy for voids to nucleate and grow. So, the nucleation sites of voids not only affected by phase interface, but also by the effects of grain boundary types within a phase.

However, from Fig. 11(b), it was found that in the same region, 

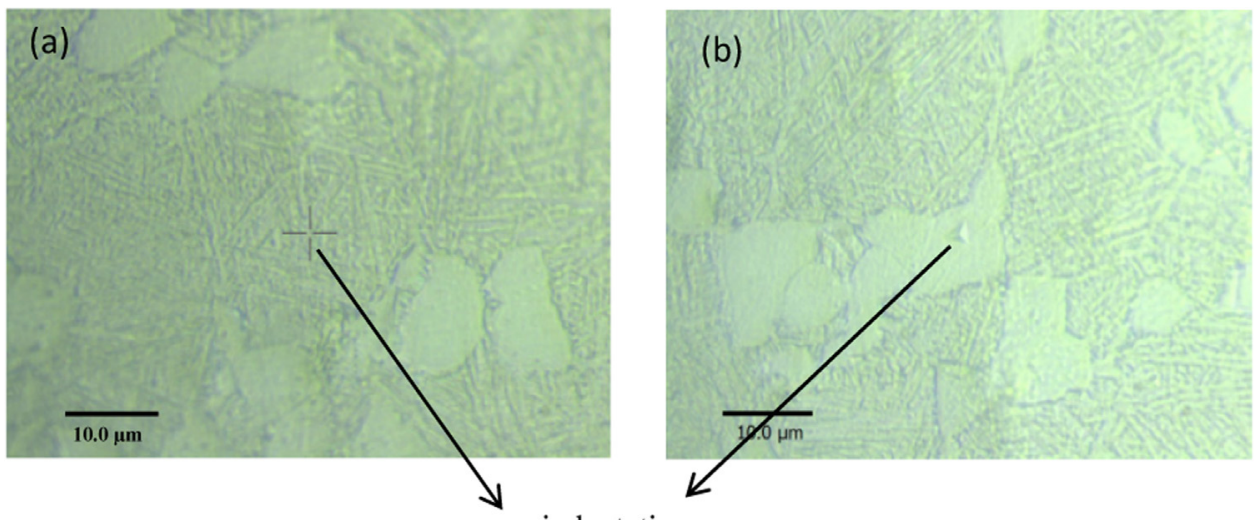

indentation

Fig. 8. The indentation of two test points.

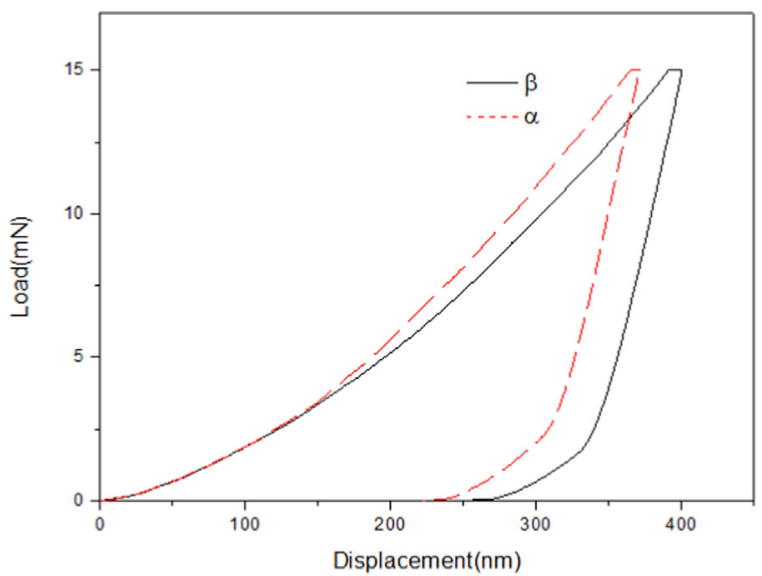

Fig. 9. Displacement-load loading and unloading curves of $\alpha$ phase and $\beta$ phase.

Table 4

The related experimental data of nano indentation.

\begin{tabular}{llllll}
\hline Phase & $\begin{array}{c}\text { Density } \\
(\mathrm{g} / \\
\left.\mathrm{cm}^{3}\right)\end{array}$ & $\begin{array}{l}\text { Nano- } \\
\text { hardness } \\
(\mathrm{GPa})\end{array}$ & $\begin{array}{l}\text { Elastic } \\
\text { modulus } \\
(\mathrm{GPa})\end{array}$ & $\begin{array}{l}\text { sound } \\
\text { velocity } \\
\left(C_{0}\right) \\
(\mathrm{km} / \mathrm{s})\end{array}$ & $\begin{array}{l}\text { Estimated value of } \\
\text { shock impedance }(\mathrm{Z}) \\
\left(\frac{\mathrm{g}}{\mu \mathrm{s} \cdot \mathrm{mm}^{2}} \times 10^{-3}\right)\end{array}$ \\
\hline a phase & 4.43 & 5.527 & 135.42 & 5.51 & 24.57 \\
$\beta$ phase & 4.39 & 4.295 & 113.67 & 5.09 & 22.35 \\
\hline
\end{tabular}

there was a void nucleated at point (2), but not in point (3. To probe this observation further, a Taylor factor(TF) analysis [33] was carried out using the crystallographic data from the EBSD scan. TF is an effective reference quantity of assessing the grains' ability of resisting plastic deformation, and the grains with lower TF value(e.g.blue grain)would possess more independent active slip system.

As shown in Fig. 12, comparing the three points (1) (2) (3), found that the voids were mainly nucleated at grain boundary triple points(1) (2) which consist of grains with higher TF and lower TF. This is because the slip system of grains with higher TF is less, it is difficult for plastic deformation to occur. However, the plastic deformation ability of the adjacent grains with lower TF is stronger, which makes the difference of plastic deformation capacity of this grains was larger, and it was easy for this points to produce stress concentration. Thus this sites became the prior nucleation position of the voids. However, there was no voids nucleated at the triple point (3, which was due to the small difference of the adjacent grain TF. The difference of plastic deformation capacity on both sides of the grain boundary is not significant, so it is not easy for voids to nucleate. Voids nucleation was not random. The difference of orientation induced the plastic deformation ability of grains was different, and the voids prefer nucleating in the boundary of grains with strong and weak ability of plastic deformation, which was consistent with the conclusions of Wielewski et al. [24,34-36]. According to Table 1, the grain size of sample two is smaller, which means the area of grain boundary is larger. Because the voids were nucleated at the grain boundary within a phase, the expansion rate of single void was higher, which also explained the phenomenon that the size of voids of sample two was larger than that of sample one in the multidimensional analyses.

The nucleation of voids not only influenced by the types of grain

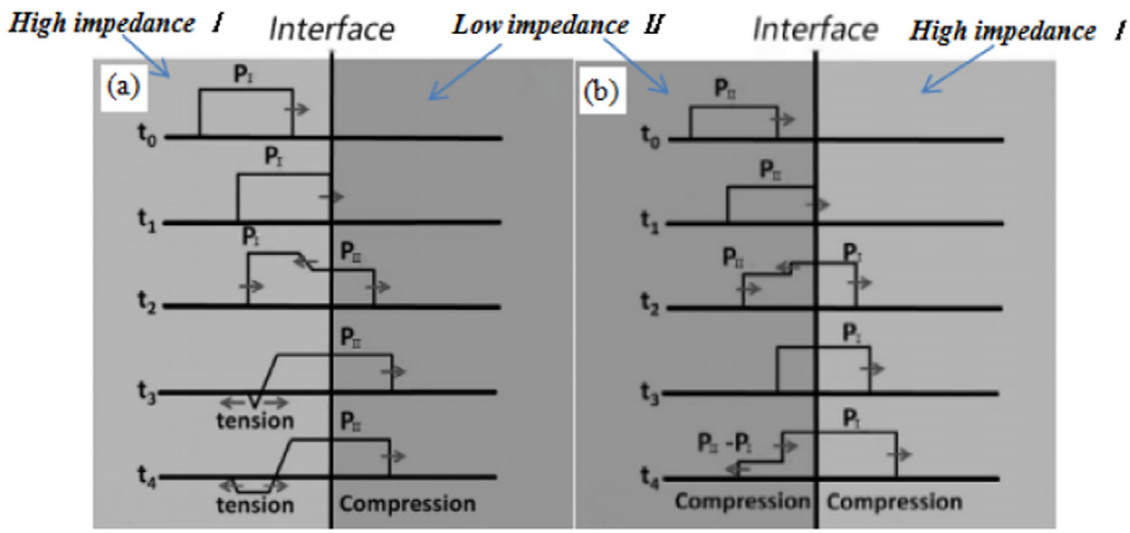

Fig. 10. (a) shock wave propagating from material I with high impedance to material II with low impedance. (b) shock wave propagating from material II with low impedance to material I with high impedance [24]. 


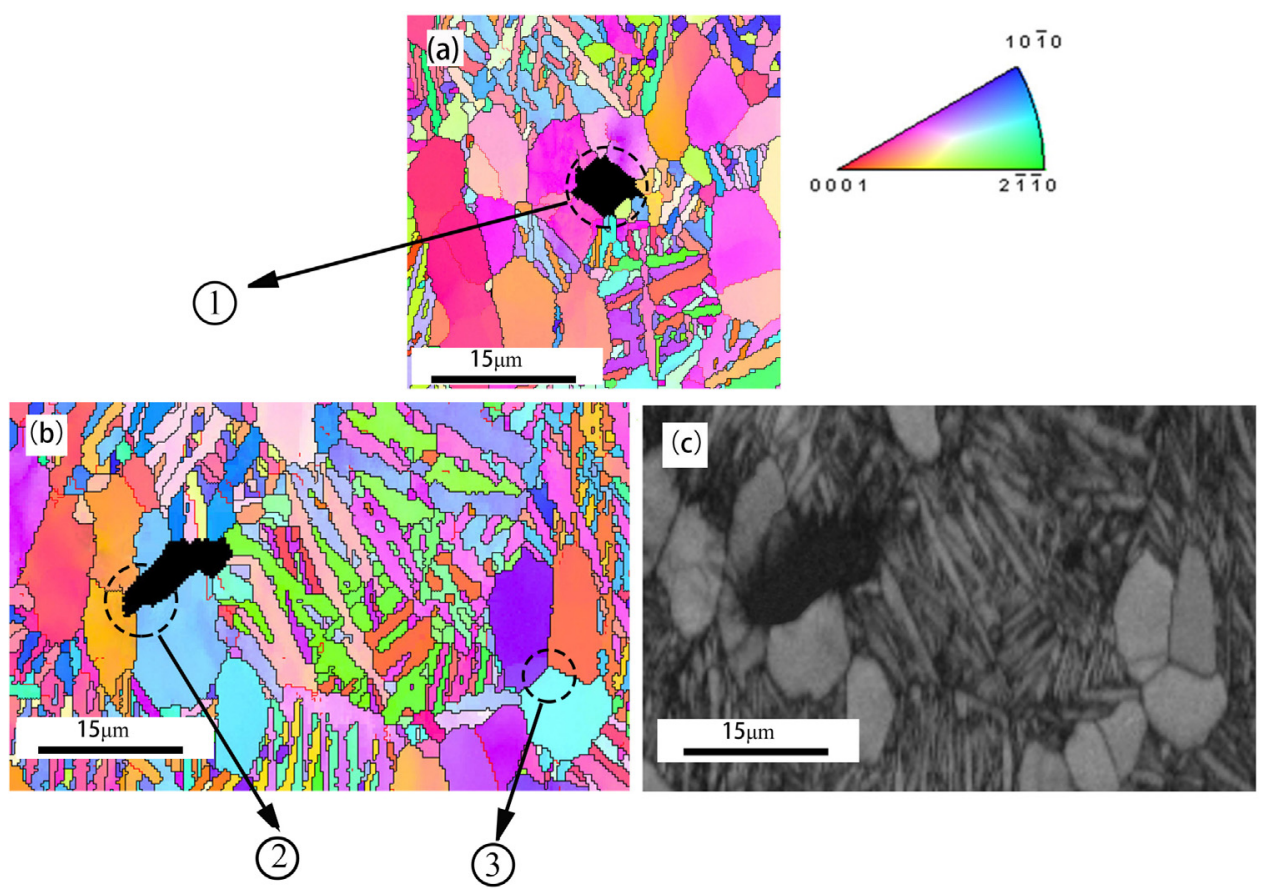

Fig. 11. Orientation maps near the voids (a) sample one (b) sample two (c) quality comparison diagram of EBSD of (b) region.

boundary, but also by the TF of grains, that is, the voids prefer nucleating in the grain boundary triple points, which consist of grains with large differences of orientation and $\mathrm{TF}$ value within a phase.

\section{Conclusion}

In this paper, the effect of phase interface on the spall behavior of Ti-6Al-4V was studied by using the dynamic loading experiment of single-stage light gas gun. The FSV during the loading process was analyzed, and the metallography, nano indentation, XRCT, EBSD techniques were used to analyze the incipient spallation of samples after soft recovery. The following main conclusions were obtained:

1. From the analysis of 2-D metallographic, the voids were not nucleated at phase interface ("weak link"), but within the a phase. According to the theory of impact, different phase with different shock impedance may affect the spread of shock waves and the nucleation sites of voids. And only when shock wave transmit from a material with high impedance to a material with low impedance, a tensile pulse would be formed within the material with high

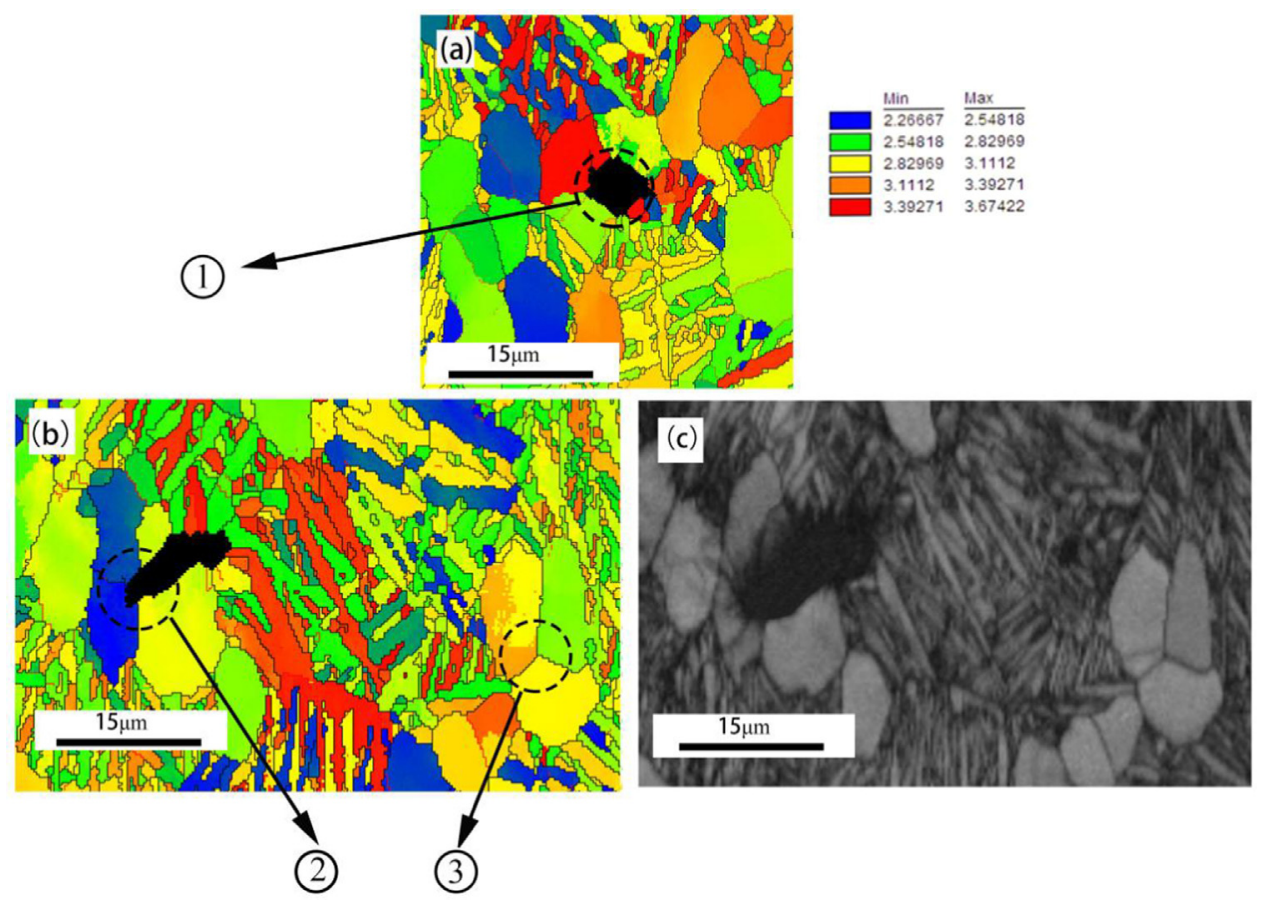

Fig. 12. Taylor Factor map of sample after the detonation, different color represent grains with different TF values. (a) sample one (b) sample two (c)quality comparison diagram of EBSD of (b) region. 
impedance. If this tensile pulse is large enough, a spallation would be formed.

2. Through the analyses of FSV, OM and XRCT, the spall strength of sample one was lower than that of sample two. The number and density of voids in sample one were more than those of sample two, while the mean size of voids of sample one were smaller than that of sample two. This is because the content of a phase in sample one is higher than that of sample two, which means sample one owns more nucleation sites. This would lead to more voids and reduce the spall strength of sample one. The grain size of sample two is smaller, which means the area of grain boundary is larger, and because the voids were nucleated at the grain boundary within a phase, the growth rate of single void is higher thus the growth rate of single void is higher. So the size of voids in sample one was smaller.

3. Voids nucleation is not random, but prefer nucleating at grain boundary triple points which consist of grains with larger differences of orientation and TF value within a phase. This is because the difference of the plastic deformation capacity of the two sides of this grain boundary is larger, and it is easy for this boundaries to produce stress concentration and become the prior nucleation position of the voids. This also explains that under the same load condition, some a phases with voids nucleation, and other a phases without voids nucleation.

\section{Acknowledge}

This work is supported by the National Natural Science Foundation of China (No. 51274245, No. 51574290)、NSAF (No. U1330126), the Opening fund of State Key Laboratory of Nonlinear Mechanics.

\section{References}

[1] T.H. Antoun, D.R. Curran, S.V. Razorenov, L. Seaman, G.I. Kanel, A.V. Utkin, Spall fracture, Springer, New York, 2003.

[2] M.A. Meyers, Dynamic behavior of materials, John Wiley \& Sons, 1994.

[3] B. Hopkinson, A method of Measuring the pressure produced in the detonation of high Explosives or by the impact of Bullets, Philos. Trans. R. Soc. A 213A (10) (1914) 437-456.

[4] J.S. Rinehart, Some quantitative data bearing on the scabbing of metals by an explosive attack, J. Appl. Phys. 22 (5) (1951) 555-560.

[5] M.A. Meyers, C.T. Aimone, Dynamic failure of metals, Progress. Mater. Sci. 28 (3) (1983) 1-96.

[6] L. Davison, D.E. Grady, M. Shahinpoor (Eds.), High-Pressure Shock Compression of Solids II[M], Springer, New York, 1996.

[7] D.R. Curran, L. Seaman, D.A. Shockey, Dynamic failure of solids, Phys. Rep. 147 (5 \&6) (1987) 253-388, http://dx.doi.org/10.1016/0370-1573(87)90049-4.

[8] C. Williams, B. Love, Dynamic Failure of Materials, Dyn. Fail. Mater. A Rev. (2010).

[9] A.C. Koskelo, S.R. Greenfield, D.L. Paisley, K.L. McClellan, D.D. Byler, R.M. Dickerson, S.N. Luo, D.C. Swift, D.L. Tonks, P.D. Peralta, Dynamics of the onset of damage in metals under shock loading, Shock Comperssion Condens. Matter (2007) 557-560.

[10] M.D. Furnish, L.C. Chhabildas, Determination and interpretation of statistics of spatiallyresolved waveforms in spalled tantalum from 7 to $13 \mathrm{GPa}$, Int. J. Plast. 25 (2) (2009) 587-602, http://dx.doi.org/10.1016/j.ijplas.2008.12.007.

[11] J.P. Escobedo, E.K. Cerrenta, D.D. Koller, Effect of crystalline structure on intergranular failure during shock loading, JOM 66 (1) (2014) 156-164, http://dx.doi. org/10.1007/s11837-013-0798-6.

[12] J.P. Escobedo, D.D. Koller, E. Cerreta, B.M. Patterson, C.A. Bronkhorst, B.L. Hansen, D. Tonks, R. Lebensohn, Effects of grain size and boundary structure on the dynamic tensile response of copper, J. Appl. Phys. 110 (3) (2011) 26-262, http://dx.doi.org/ 10.1063/1.3607294.

[13] Y. Yang, Z.Q. Peng, X.Z. Chen, Z.L. Zhao, T.G. Tang, H.B. Hu, Q.M. Zhang, Spall behaviors of high purity copper under sweeping detonation, Mater. Sci. Eng. A 651
(2016) 636-645, http://dx.doi.org/10.1016/j.msea.2015.11.022.

[14] Y. Yang, Z. Jiang, J.X. Chen, Z.L. Guo, T.T. Gang, H.B. Hu, The characteristics of void distribution in spalled high purity copper cylinder under sweeping detonation, Philos. Mag. 98 (9) (2018) 752-765, http://dx.doi.org/10.1080/14786435.2017. 1417649.

[15] Y. Yang, Z.Q. Peng, Z.L. Guo, et al., Multidimensional study on spall behavior of high-purity copper under sliding detonation, Metall. Mater. Trans. A 46 (9) (2015) 4070-4077, http://dx.doi.org/10.1007/s11661-015-3027-9.

[16] Y. Yang, J.X. Chen, Z.Q. Peng, Z.L. Guo, T.G. Tang, H.B. Hu, Y.N. Hu, X-ray quantitative analysis on spallation response in high purity copper under sweeping detonation, Mater. Sci. Eng. A 667 (2016) 54-60, http://dx.doi.org/10.1016/j msea.2016.04.090.

[17] S.K. Yerra, G. Martin, M. Véron, Y. Bréchet, J.D. Mithieux, L. Delannay, T. Pardoen, Ductile fracture initiated by interface nucleation in two-phase elastoplastic systems, Eng. Fract. Mech. 102 (2013) 77-100, http://dx.doi.org/10.1016/j.engfracmech. 2013.02.028.

[18] R.W. Minich, J. Cazamias, M. Kumar, A. Schwartz, Effect of microstructural length scales on spall behavior of copper, Metall. Mater. Trans. A 35 (2004) 2663, http:// dx.doi.org/10.1007/s11661-004-0212-7.

[19] L.E. Murr, K.P. Staudhammer, M.A. Meyers, Metallurgical Applications of ShockWave and High-Strain-Rate Phenomena, Marcel Dekker, Inc, 1986.

[20] S.J. Fensin, J.P. Escobedo, G.T. Gray, B.M. Patterson, Dynamic damage nucleation and evolution in multiphase materials, J. Appl. Phys. 115 (20) (2014) 2035 16-2035 16-7, http://dx.doi.org/10.1063/1.4880435.

[21] S.J. Fensin, E.K. Walker, E.K. Cerreta, C.P. Trujillo, D.T. Martinez, G.T. Gray, Dynamic failure in two-phase materials, J. Appl. Phys. 118 (23) (2015) 033513-033555, http://dx.doi.org/10.1063/1.493810.

[22] S.J. Fensin, D.R. Jones, E.K. Walker, A. Farrow, S.D. Imhoff, K.D. Clarke, C. Trujillo, D.T. Martinez, G.T. Gray, E.K. Cerreta, The effect of distribution of second phase on dynamic damage, J. Appl. Phys. 120 (8) (2016) 329-335, http://dx.doi.org/10. 1063/1.4961041.

[23] E. Cerreta, S. Fensin, G. Gray Iii, et al., The role of interfaces on dynamic damage in two phase metals, AIP Conf. Proc. 1426 (1) (2012) 5001, http://dx.doi.org/10. $1063 / 1.368652$.

[24] W.Z. Han, E.K. Cerreta, N.A. Mara, I.J. Beyerlein, J.S. Carpenter, S.J. Zheng, Deformation and failure of shocked bulk Cu-Nb nanolaminates, Acta Mater. 63 (63) (2014) 150-161, http://dx.doi.org/10.1016/j.actamat.2013.10.019.

[25] Y. Yang, C. Wang, X.Z. Chen, H.B. Hu, K.G. Chen, Y.N. Fu, Effects of the phase interface on spallation damage nucleation and evolution in multiphase alloy, J. Alloy. Compd. 740 (2018) 321-329, http://dx.doi.org/10.1016/j.jallcom.2018.01. 031.

[26] Y. Yang, C. Wang, X.Z. Chen, K.G. Chen, H.B. Hu, Y.N. Fu, The void nucleation mechanism within lead phase during spallation of leaded brass, Philos. Mag. 98 (21) (2018) 1975-1990.

[27] M.B. Zellner, G.B. Vunni, Photon doppler velocimetry (PDV) characterization of shaped charge jet formation, Procedia Eng. 58 (2013) 88-97, http://dx.doi.org/10. 1016/j.proeng.2013.05.012.

[28] W.C. Oliver, Pharr, et al., Improved technique for determining hardness and elastic modulus using load and displacement sensing indentation experiments, J. Mater. Res. Home 7 (06) (1992) 1564-1583.

[29] C. Williams, D. Dandekar, K. Ramesh, Spall response of 1100-O aluminum, J. Appl. Phys. 111 (12) (2012) 43-70, http://dx.doi.org/10.1063/1.4729305.

[30] S.A. Novikov, Spall strength of materials under shock load, J. Appl. Mech. Tech. Phys. 3 (1967) 109

[31] G.V. Stepanov, V.I. Romanchenko, V.V. Astanin, Experimental determination of failure stresses under spallation in elastic-plastic waves, Inst. Probl. Strength 8 (1977) 96.

[32] G.T. Gray III, Annu, High-strain-rate deformation: mechanical behavior and deformation substructures induced, Annu. Rev. Mater. Res. 42 (2012) 285-303, http://dx.doi.org/10.1146/annurev-matsci-070511-155034.

[33] G.I. Taylor, Plastic strain in metals, J. Inst. Met. 62 (1938) 307.

[34] F.P.E. Dunne, D. Rugg, On the mechanisms of fatigue facet nucleation in titanium alloys, Fatigue Fract. Eng. Mater. Struct. 31 (11) (2008) 949-958, http://dx.doi. org/10.1111/j.1460-2695.2008.01284.x.

[35] F.P.E. Dunne, D. Rugg, A. Walker, Lengthscale-dependent, elastically anisotropic, physically-based hcp crystal plasticity: application to cold-dwell fatigue in Ti alloys, Int. J. Plast. 23 (6) (2007) 1061-1083, http://dx.doi.org/10.1016/j.ijplas.2006.10. 013.

[36] D. Rugg, M. Dixon, F.P.E. Dunne, Effective structural unit size in titanium alloys, J. Strain Anal. Eng. Des. 42 (42) (2007) 269-279, http://dx.doi.org/10.1243/ 03093247 JSA273. 